\title{
Pneumomediastinum and subcutaneous
} emphysema as complication in COVID-19 patient with high CT severity score: Two case reports

\author{
Ravi R Kumar, Alok K Singhai, Shantanu V Lokare1, Saumil P Pandya \\ Department of Radiology, Pulse Hitech Health Services, Borivali West, 'Department of Medicine, Dhanashri Hospital, \\ Borivali West, Mumbai, Maharashtra, India
}

Correspondence: Dr. Ravi R Kumar, A1, 503, Building Number-5, Siddharth Nagar CHS, Siddharth Nagar, Borivali East, Mumbai - 400066 , Maharashtra, India. E-mail: drravistar@gmail.com

\begin{abstract}
Coronavirus disease 2019 (COVID-19) is caused due to infection by severe acute respiratory syndrome virus coronavirus 2 (SARS-CoV-2). It is highly infective virus resulting in recent on-going pandemic and causing multisystem involvement predominantly affecting respiratory system. The most common presenting symptoms are fever, dry cough and breathlessness. The role of Computerized tomography (CT) is crucial especially in those patient having negative (rRT-PCR) but with high clinical suspicion, for prognosis and follow up. CT imaging findings mainly consists of multiple patchy bilateral ground-glass opacity (GGO) with or without consolidation and interlobular septal thickening with a peripheral or posterior distribution, mainly involving the lower lobes, depending upon the stage of disease. We present two case report of high CT severity score COVID-19 infection on non-invasive ventilation (NIV) having rare complication of pneumomediastinum and subcutaneous emphysema apart from typical COVID pattern lung findings during their course of admission in the hospital.
\end{abstract}

Key words: Complications; COVID-19; CT chest; pandemic; prognosis spontaneous pneumomediastinum; subcutaneous emphysema

\section{Introduction}

Coronavirusdisease 2019(COVID-19)iscaused duetoinfection by severe acute respiratory syndrome virus coronavirus 2 (SARS-CoV-2). The disease was first reported in December 2019 in Wuhan, (capital city of Hubei Province China) and has been spreading globally since then resulting in pandemic. ${ }^{[1]}$ The most common presenting symptoms are fever, dry cough and breathlessness. Other less common symptoms include abdominal pain, myalgia, diarrhoea,

\begin{tabular}{|c|c|}
\hline \multicolumn{2}{|c|}{ Access this article online } \\
\hline Quick Response Code: & \multirow[b]{2}{*}{$\begin{array}{l}\text { Website: } \\
\text { www.ijri.org }\end{array}$} \\
\hline \multirow{2}{*}{ 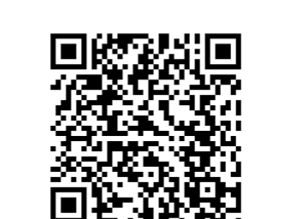 } & \\
\hline & $\begin{array}{l}\text { DOI: } \\
\text { 10.4103/ijri.IJRI_629_20 }\end{array}$ \\
\hline
\end{tabular}

sore throat, fatigue and loss of smell. Real time-reverse transcription polymerase chain reaction (rRT-PCR) from a nasopharyngeal swab helps in diagnosis. ${ }^{[2]}$

The role of Computerized tomography (CT) is crucial especially in those patient having negative rRT-PCR but

This is an open access journal, and articles are distributed under the terms of the Creative Commons Attribution-NonCommercial-ShareAlike 4.0 License, which allows others to remix, tweak, and build upon the work non-commercially, as long as appropriate credit is given and the new creations are licensed under the identical terms.

For reprints contact: WKHLRPMedknow_reprints@wolterskluwer.com

Cite this article as: Kumar RR, Singhai AK, Lokare SV, Pandya SP. Pneumomediastinum and subcutaneous emphysema as complication in COVID-19 patient with high CT severity score: Two case reports. Indian J Radiol Imaging 2021;31:S187-91.

Received: 20-Jul-2020

Accepted: 22-Oct-2020

Revised: 14-Sep-2020 Published: 23-Jan-2021 
with high clinical suspicion, for prognosis and follow up. CT imaging findings mainly consists of multiple patchy bilateral ground-glass opacity (GGO) with or without consolidation and interlobular septal thickening with a peripheral or posterior distribution, mainly involving the lower lobes, depending upon the stage of disease. Uncommon features can be listed as pleural and pericardial effusion, lymphadenopathy, cavitation, CT halo sign, and pneumothorax, pneumomediastinum, soft tissue emphysema in subcutaneous, soft tissue planes. ${ }^{[3,4]}$

In this two case report, we present two patients of high CT severity score COVID-19 infection on non-invasive ventilation (NIV) having rare complication of pneumomediastinum and extensive subcutaneous emphysema apart from typical COVID pattern lung findings during their course of admission in the hospital and few case reports has been published till now to the best knowledge of the author.

\section{Case History}

Case 1

A 58-year-old male patient was admitted to emergency department of hospital in Mumbai on $15^{\text {th }}$ June 2020, having complain of fever, and sore throat and intermittent cough since 7 days which progressed to shortness of breath. On physical examination, temperature of the patient was $100.5^{\circ} \mathrm{F}$ (Fahrenheit $/ 38.0^{\circ}$ Celsius), heart rate (HR) and respiration rate (RR) were 112 and 25 per minute, respectively. Blood pressure was $110 / 80 \mathrm{mmHg}$. The initial SpO2 (saturation of peripheral oxygen) was 75\% without oxygen and $90 \%$ with nasal oxygen mask. His lung examination revealed bilateral crepitation. No significant past medical history found.

Biochemical investigations were done which revealed normal white cell count-6100/mm3 with elevated neutrophil count $-87 \%$ and lymphopenia-9\%, raised CRP- $61.5 \mathrm{mg} / \mathrm{L}$, high ESR-125 mm/hr. His D-dimer was elevated-3417 ng/ml and serum ferritin was normal-138.7 $\mathrm{ng} / \mathrm{ml}$.

Chest X-ray was suggestive of bilateral patchy infiltrates. In the given clinical scenario and on going pandemic, COVID-19 was suspected and rRT-PCR done suggestive of COVID-19. The patient admitted in ward and Supplemental oxygen with non-invasive ventilation-NIV (BiPAP- Bi-level positive airway pressure) started, was given antibacterial (cefoperazone-sulbactam, azithromycin), antiviral (oseltamavir), and corticosteroid treatments (methylprednisolone), tablet hydroxychloroquine sulphate (HCQS) and other symptomatic treatment in the form of antitussives, and bronchodilators, antacid and vitamins c, zinc were added.

On day $10^{\text {th }}$ of admission, patient developed swelling and tightness in the region of chest, neck and proximal right upper extremity and difficulty in swallowing. Crepitus were noted clinically and X-ray revealed subcutaneous emphysema. This was followed by chest CT scan to look for other complication. The CT scan revealed widespread bilateral GGOs, interlobular septal thickening predominantly in lower lobes consistent with COVID-19 lung involvement with high CT severity score of $16 / 25$. Additionally, pneumomediastinum, extensive subcutaneous emphysema in the neck, chest wall and proximal upper extremity were seen [Figures 1 and 2]. Subcutaneous drain were placed and optimal NIV (BiPAP) having low PEEP (positive end expiratory pressure) of $5 \mathrm{~cm}$ of $\mathrm{H} 2 \mathrm{O}$ with Fio 2 of $100 \%$ used and routine treatment continued after which subsequent symptomatic improvement noted.

On day 19 of admission patient again complained of excessive pain in the neck region however with normal vitals and Spo2 for which repeat CT scan done for chest and neck region which reveal significant decrease in the size of GGO, pneumomediastinum and subcutaneous emphysema as compared to previous scan with development of parenchymal bands [Figure 3]. No other imaging findings could be attributed to the neck pain which subsequently improved after conservative management. General condition of the patient improved day by day and was discharged from hospital.

\section{Case 2}

A 67-year-old male patient in Mumbai with 5 day history of dry cough, severe generalized weakness and body-ache,
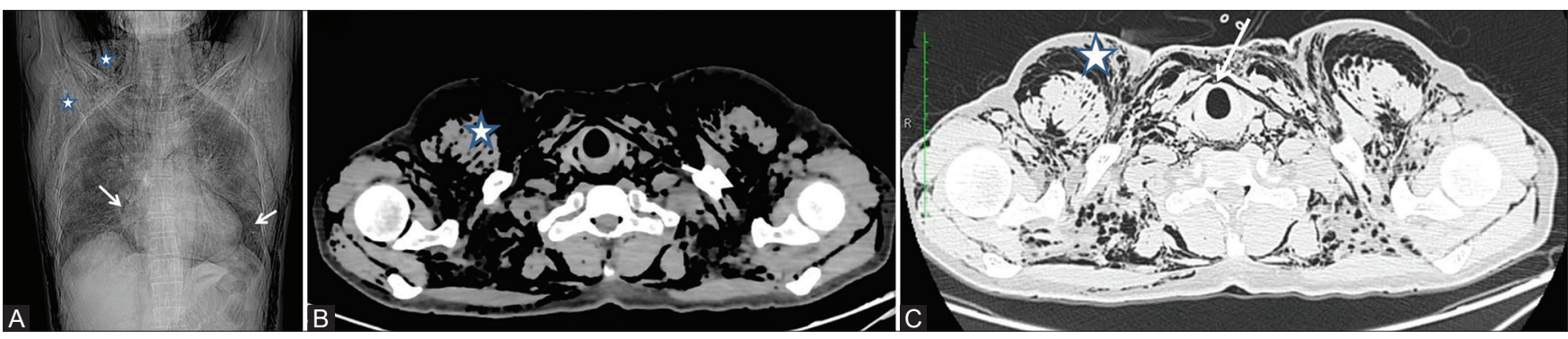

Figure 1 (A-C): A-C: NCCT topographical, axial mediastinal and lung window images at thoracic inlet of rRT-PCR confirmed COVID patient (Case1 on day 10 of admission) developed sudden onset swelling and tightness in chest, neck and difficulty in swallowing, showing subcutaneous and soft tissue emphysema (star mark) and pneumomediastinum (white arrow) 

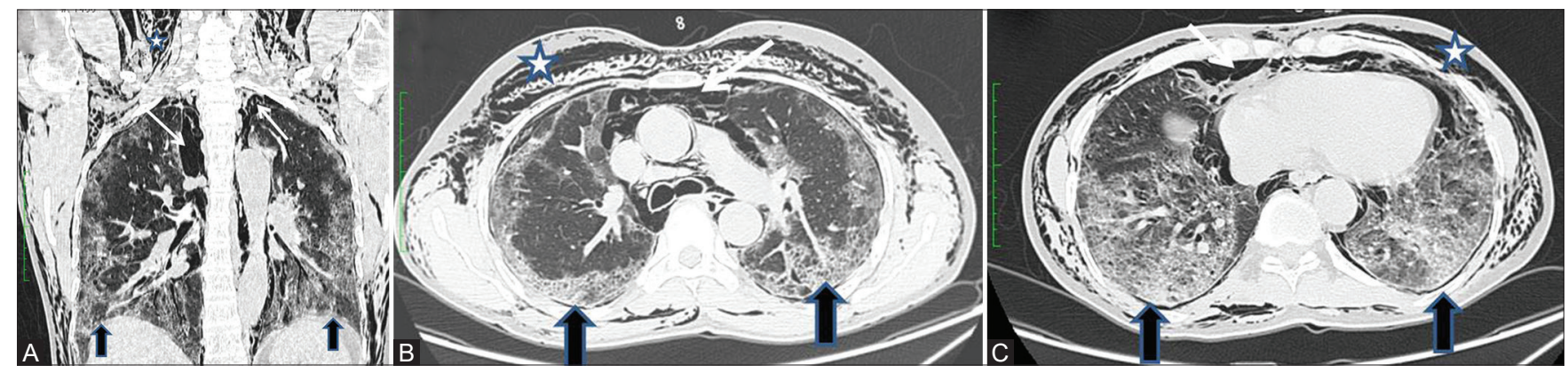

Figure 2 (A-C): A-C: NCCT Coronal and axial lung window of rRT-PCR confirmed COVID patient (case1 on day 10 of admission, same patient as in Figure 1), showing subcutaneous and soft tissue emphysema (star mark) and pneumomediastinum (white arrow) along with extensive GGO, septal thickening and consolidations (Black arrow)

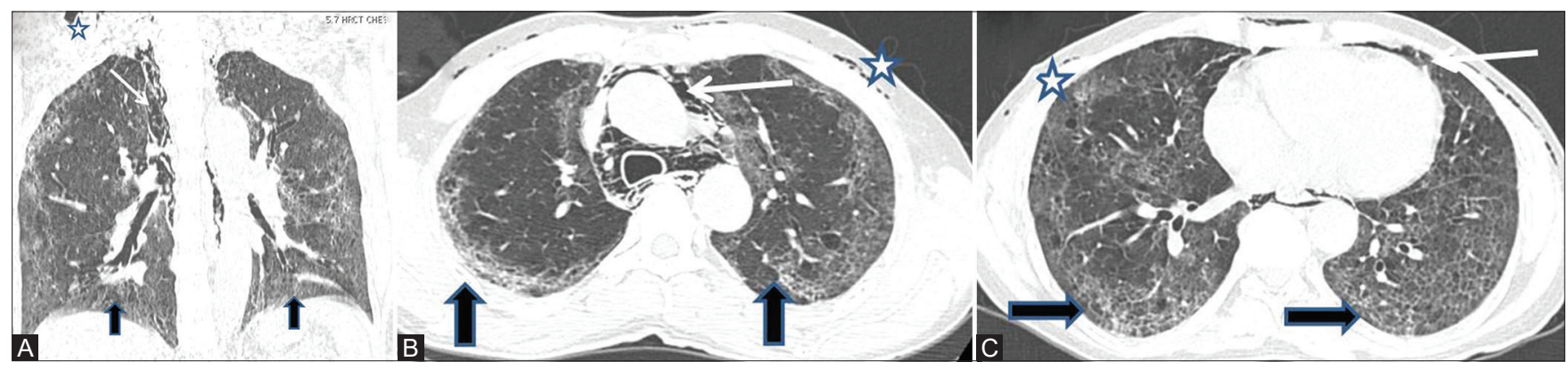

Figure 3 (A-C):A-C: NCCT Coronal and axial lung window of follow up rRT-PCR confirmed COVID patient (case 1 on day 19 of admission) showing significant decrease in subcutaneous emphysema (star mark) and pneumomediastinum (white arrow) along with decrease in GGO, septal thickening and consolidations and initial development of mild parenchymal bands (Black arrow)

3 days history of shortness of breath, afebrile was admitted to Hospital on July1, 2020, rRT-PCR was conducted on OPD basis which came positive after which the patient was admitted. On physical examination, patient was afebrile having temperature- $98.2^{\circ} \mathrm{F}\left(36.7^{\circ} \mathrm{C}\right), \mathrm{HR}-85 /$ minute and RR-30/minute. Blood pressure was 130/90 $\mathrm{mmHg}$. The initial SpO2 was $60 \%$ without oxygen and $90 \%$ with BiPAP (Optimal NIV having low PEEP of $5 \mathrm{~cm}$ of $\mathrm{H} 2 \mathrm{O}$ with Fio2 of $100 \%$ used). His lung examination revealed bilateral crepitation. No significant past medical history found.

Biochemical investigations done which revealed normal white cell count-5300/mm3 with elevated neutrophil count-78\% and lymphocyte count-15\% (lymphopenia), raised CRP-45.5 mg/L. His D-dimer was $4250 \mathrm{ng} / \mathrm{ml}$ (extremely high) and normal serum ferritin-202.7 ng/ml. Chest X-ray done, suggestive of bilateral patchy infiltrates.

The patient was admitted in ICU and Supplemental oxygen with NIV (BiPAP) started, was given antibacterial (cefoperazone-sulbactam, azithromycin), antiviral (oseltamavir), and corticosteroid (methylprednisolone), tablet HCQS, Enoxaparin sodium (clexane). Other symptomatic treatment in the form of antitussives, and bronchodilators, antacid, antiemtics, zinc and vitamins c were added.

Condition of the patient did not improve significantly and on day 3 of admission the HR-82/min, RR-22/min,
Spo2-80\% (on BiPAP), BP-150/90 noted. Patient still complain of mild shortness of breath On day 4 of admission breathlessness increased and no significant improvement in other parameters noted for which CT scan was done to look for complication which revealed multiple extensive GGOs, interlobular septal thickening with parenchymal consolidation, combined with pneumomediastinum and subcutaneous emphysema with high CT severity score of 18/25 [Figure 4]. This was followed by Injection remdesivir and Tocilizumab and tablet clarithromycin and indomethacin were added. Two episode of hemoptysis was noted on day 4 of admission following which dose of clexane was reduced. Patient was intubated and mechanical ventilation started along with chest tube placement but patient soon deteriorated and succumbed.

\section{Discussion}

There is serious concern regarding outbreak of COVID-19 viral infection ever since its origin from Wuhan, China and which has spread globally during recent time, the disease characteristics features and clinical spectrum well known, diagnosis and treatment protocols of the disease are currently evolving. COVID-19 primarily spreads by small droplets during close contact. ${ }^{[2]}$ The median incubation period was reported as 4 days. ${ }^{[3]}$ It is reported that virus access cells via angiotensin-converting enzyme-2 which is plenty in type II alveolar cells of the lungs. Thus, the lungs are the most affected organs by COVID-19. ${ }^{[4]}$ 


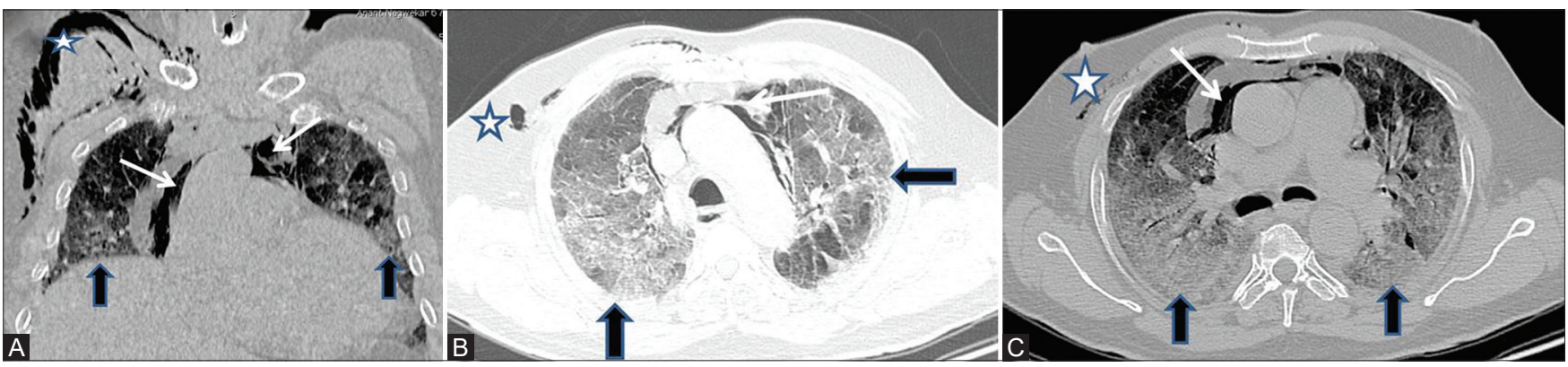

Figure 4 (A-C): A-C: NCCT Coronal and axial lung window of rRT-PCR confirmed COVID patient (case2 on day 4 of admission) in ICU, having worsening of breathlessness showing subcutaneous emphysema (star mark) and pneumomediastinum (white arrow) along with extensive ground glass opacities, septal thickening and consolidations (Black arrow)

Even the majority of cases result in mild symptom, some cases develops viral pneumonia and multiorgan failure. ${ }^{[2]}$ The common clinical presentation include fever (85-90\%), cough $(65-70 \%)$, disturbed taste and smell $(40-50 \%)$, fatigue (35-40\%), sputum production (30-35\%), shortness of breath (15-20\%). Less common clinical features are myalgia/arthralgia, headaches, sore throat, chills, and pleuritic pain. The Rare manifestations are nausea, vomiting, nasal congestion, diarrhoea, palpitations, chest tightness, hemoptysis, confusion, seizures, paraesthesia, and altered consciousness. ${ }^{[5-8]}$

In patients with COVID-19, chest CT is recommended in suspected patients for both initial diagnosis and follow up and in suspected complication. ${ }^{[2]}$ Moreover, CT findings has found to be diagnostic in cases with initial rRT-PCR test was false-negative. ${ }^{[2,9]}$ The typical findings on $\mathrm{CT}$ are bilateral, sub pleural, basal GGOs and inter-/intra-lobular septal thickening, air-space consolidation, bronchovascular thickening, traction bronchiectasis. ${ }^{[10-16]}$

Atypical CT finding seen in a small minority of patients should raise concern for superadded bacterial pneumonia or other diagnoses. These include mediastinal lymphadenopathy, pleural effusions, tiny pulmonary nodules, tree-in-bud, pneumothorax, cavitation, bronchial wall thickening. ${ }^{[2,10,11,13,17]}$

Pneumomediastinum is the presence of extra luminal gas within the mediastinum. Subcutaneous emphysema occurs when air gets into the tissues under the skin and in the soft tissues. When it is of low severity, it causes minimal symptoms, is not dangerous in itself, and requires no specific treatment. If it involves the deeper tissues of the thoracic outlet, chest, and abdominal wall, it will be a severe, stressful, and life threatening condition. It can be complicated by restriction of full lung re-expansion and can lead to high airway pressure, severe respiratory acidosis, ventilator failure, pacemaker malfunction, airway compromise, and tension phenomena. ${ }^{[18-25]}$

The complication of Pneumomediastinum, subcutaneous emphysema in extensive parenchymal lesion with high
CT severity score indicates severe destruction of the alveolar membrane and therefore can result in worsening of clinical results. ${ }^{[25,26]}$ Both of our patients had high CT severity score (Case 1- 16/25 and Case 2- 18/25) graded according to Marco Francone et al..$^{[26]}$ The overall incidence of pneumomediastinum and sub-cutaneous emphysema in COVID-19 patients on NIV (pressure controlled ventilation mode having low PEEP of $5 \mathrm{~cm} \mathrm{H2O}$ ) is very low and no dedicated study has been found till date in literature.

In this case reports we highlight rare but serious clinical scenario of the high CT severity score COVID-19 infection complicated with pneumomediastinum and subcutaneous emphysema and emphasizes the importance of CT imaging apart from the common imaging patterns for guiding appropriate management. This complication is unlikely because of NIV (optimal low mode parameters used for our patients) and rather is due to COVID-19 induced lung damage itself with other precipitating factor like cough. Diagnosis and treatment in early stage before progression to high severity, optimal medical management for cough if present and use of pressure controlled ventilation with low PEEP of $5 \mathrm{~cm}$ of $\mathrm{H} 20$ if required would help in preventing complication.

\section{Declaration of patient consent}

The authors certify that they have obtained all appropriate patient consent forms. In the form the patient(s) has/have given his/her/their consent for his/her/their images and other clinical information to be reported in the journal. The patients understand that their names and initials will not be published and due efforts will be made to conceal their identity, but anonymity cannot be guaranteed.

Financial support and sponsorship

Nil.

Conflicts of interest

There are no conflicts of interest.

\section{References}

1. Hui DS, Azhar EI, Madani TA, Ntoumi F, Kock R, Dar O. The continuing 2019-nCoV epidemic threat of novel coronaviruses 
to global health - the latest 2019 novel coronavirus outbreak in Wuhan, China. Int J Infect Dis 2020;91:264-6.

2. Salehi S, Abedi A, Balakrishnan S, Gholamrezanezhad A. Coronavirus disease 2019 (COVID-19): A systematic review of imaging findings in 919 patients. AJR AM J Roentgenol 2020;14:1-7.

3. Guan WJ, Ni ZY, Hu Y, Liang WH, Ou CQ, He JX. Clinical characteristics of coronavirus disease 2019 in China. N Engl J Med 2020;382:1708-20.

4. Letko M, Marzi A, Munster V. Functional assessment of cell entry and receptor usage for SARS-CoV-2 and other lineage B betacoronaviruses. Nat Microbiol 2020;5:562-9.

5. Zheng YY, Ma YT, Zhang JY, Xie X. COVID-19 and the cardiovascular system. Nat Rev Cardiol 2020;17:259-60.

6. Casey K, Iteen A, Nicolini R, Auten J. COVID-19 pneumonia with hemoptysis: Acute segmental pulmonary emboli associated with novel coronavirus infection. Am J Emerg Med 2020;38:1544.e1-3.

7. Rogers J, Chesney E, Oliver D, Pollak TA, McGuire P, Fusar-Poli P, et al. Psychiatric and neuropsychiatric presentations associated with severe coronavirus infections: A systematic review and meta-analysis with comparison to the COVID-19 pandemic. Lancet Psychiatry 2020;7:611-27.

8. Wu Y, Xu X, Chen Z, Duan J, Hashimoto K, Yang L, et al. Nervous system involvement after infection with COVID-19 and other coronaviruses. Brain Behav Immun 2020;87:18-22.

9. Xie X, Zhong Z, Zhao W, Zheng C, Wang F, Liu J. Chest CT for typical 2019-nCoV pneumonia: Relationship to negative RT-PCR testing. Radiology 2020;296:E41-5.

10. Perlman S. Another decade, another coronavirus. N Engl J Med 2020;382:760-2.

11. Jeffrey PK, Brent PL, Jonathan HC, Brett ME, Loren HK. Essentials for radiologists on COVID-19: An update-radiology scientific expert panel. Radiology 2020;296:E113-4.

12. Wang $\mathrm{D}, \mathrm{Hu} \mathrm{B}, \mathrm{Hu} \mathrm{C}, \mathrm{Zhu} \mathrm{F}$, Liu $\mathrm{X}$, Zhang J, et al. Clinical Characteristics of 138 Hospitalized Patients With 2019 Novel Coronavirus-Infected Pneumonia in Wuhan, China. JAMA 2020;323:1061-9.

13. Pan F, Ye T, Sun P, Gui S, Liang B, Li L, et al. Time course of lung changes on chest CT during recovery from 2019 novel coronavirus (COVID-19) pneumonia. Radiology 2020;295:715-21.

14. Shi H, Han X, Jiang N, Cao Y, Osamah A, Gu J, et al. Radiological findings from 81 patients with COVID-19 pneumonia in Wuhan, China: A descriptive study. Lancet Infect Dis 2020;20:425-34.

15. Wei Z, Zheng Z, Xingzhi X, Qizhi Y, Jun L. Relation between chest $\mathrm{CT}$ findings and clinical conditions of coronavirus disease (COVID-19) pneumonia: A multicenter study. AJR 2020;214:1072-7.

16. Pan Y, Guan H, Zhou S, Wang Y, Li Q, Zhu T, et al. Initial CT findings and temporal changes in patients with the novel coronavirus pneumonia (2019-nCoV): A study of 63 patients in Wuhan, China. Eur Radiol 2020;30:3306-9.

17. Rodrigues JC, Hareb SS, Edeyc A, Devarajd A, Jacobe J, Johnstoneg A, et al. An update on COVID-19 for the radiologist-A British society of Thoracic Imaging statement. Clin Radiol 2020;75:323-5.

18. Sahn SA, Heffner JE. Spontaneous pneumothorax. N Engl J Med 2000;342:868-74.

19. Dehnadi A, Ebrahimi H, Karkan MF, Jahromi SK, Maafi AA, et al. Classification and management of subcutaneous emphysema: A 10-year experience. Indian J Surg 2015;77:673-7.

20. Ucpinar BA, Sahin C, Yanc U. Spontaneous pneumothorax and subcutaneous emphysema in COVID-19 patient: Case report. J Infect Public Health 2020;13:887-9.

21. Vinuta M, Rana AT. Spontaneous pneumomediastinum in COVID-19. BMJ Case Rep 2020;13:e236519.

22. Changyu Z, Chen G, Yuanliang X, Maosheng X. COVID-19 with spontaneous pneumomediastinum. Lancet Infect Dis 2020;20:510.

23. Wang W, Gao R, Zheng Y, Jiang L. COVID-19 with spontaneous pneumothorax, pneumomediastinum and subcutaneous emphysema. J Travel Med 2020;27:taaa062. doi: 10.1093/jtm/ taaa062.

24. Sylvie K, Nawfal H, Meryem H, Youssef A, Meryem B, Mounia S, et al. Spontaneous pneumomediastinum occurring in the SARS-COV-2 infection. IDCases 2020;21:e00806.

25. Jesse ML, María LP, Aurea DT, Silvia OV. Pneumomediastinum and spontaneous pneumothorax as an extrapulmonary complication of COVID-19 disease Emerg Radiol 2020:1-4. doi: 10.1007/ s10140-020-01806-0.

26. Marco F, Franco I, Giorgio MM, Simona C, Francesco C, Lucia M, et al. Chest CT score in COVID-19 patients: Correlation with disease severity and short-term prognosis. Eur Radiol. 2020;1-10. doi: 10.1007/s00330-020-07033. 